\title{
Knowledge sharing practice and its associated factors of healthcare professionals of public hospitals, Mekelle, Northern Ethiopia
}

\author{
Teklit Gebretsadik ${ }^{1,2}$, Gebremeskel Mirutse ${ }^{2}$, Kidane Tadesse ${ }^{2, *}$, Wondwossen Terefe ${ }^{2}$ \\ ${ }^{1}$ Department of computing, EIT-M, Mekelle University, Mekelle, Ethiopia \\ ${ }^{2}$ Department of Public Health, College of Health Sciences, Mekelle University, Mekelle, Ethiopia
}

\section{Email address:}

tege19720@gmail.com (T. Geberetsadik), gebramskelmirutse@yahoo.com (G. Mirutse), Kiducs98@yahoo.com (K. Tadesse), wlerebo@uwc.ac.za (W.Terefe)

\section{To cite this article:}

Teklit Gebretsadik, Gebremeskel Mirutse, Kidane Tadesse, Wondwossen Terefe. Knowledge Sharing Practice and its Associated Factors of Healthcare Professionals of Public Hospitals, Mekelle, Northern Ethiopia. American Journal of Health Research.

Vol. 2, No. 5, 2014, pp. 241-246. doi: 10.11648/j.ajhr.20140205.14

\begin{abstract}
Knowledge is defined as human expertise, which is found in peoples mind and gained thorough experiences and interaction. Knowledge sharing is a social interaction culture, involving the exchange of employee knowledge and skills among colleagues within an organization. The main aim of this study was to investigate the knowledge sharing practice. Using cross-sectional study design data was collected from 305 random selected health professionals. STATA version 11 was used to analyze the data. Finally Logistic regression was used to assess the presence of the association between dependent and independent variables. Of the total participant $49.18 \%$ have knowledge sharing practice. The significant predictors of knowledge sharing practice were; motivation to transfer knowledge, salary increment, supportive leadership, knowledge sharing opportunity. The study revealed that there is still lower level of knowledge sharing, which is affected by leadership, openness, opportunity, amount of monthly income and staff motivation.
\end{abstract}

Keywords: Knowledge Sharing, Knowledge Transfer, and Knowledge Management Practice

\section{Background}

Knowledge is defined as human expertise, which is found in peoples mind and gained through experience, interaction and the like. Thus knowledge sharing enables shortening the learning cycle for new employees, retains experiences from serving staff, helps staff members to reflect on their experience and facilitates knowledge retrieval and use. (1-5).

The paradigm that "knowledge is power, so if it is spread, it will cause somebody to lose his/her personal guarantee", limitation of time and low appreciation to the knowledge contributor are factor of knowledge sharing among individuals (6).

Healthcare organizations should have the culture of knowledge sharing practices to make better use of the knowhow, experiences and skills of their healthcare professionals. As a result, the healthcare workers enable to implement their best practices and generate new ideas and better healthcare quality service can be delivered (7). A study conducted in Taiwan which examined factors affecting knowledge sharing practice knowledge selfefficacy, top management support and organization rewards and information and communication technology use were strongly associated with knowledge sharing. (25)

The number of healthcare professionals is increased from time to time in Ethiopia. However there is also high turn over because of different factors. Therefore, to introduce knowledge-sharing practices in formal way knowing the situation and factors affecting is mandatory for the improvement of quality healthcare services $(8,9)$.

\section{Methods and Materials}

\subsection{Study Setting and Population}

The study was conducted on March 2013 in public Hospitals of Mekelle city Tigray Regional State about 773 $\mathrm{Km}$ far from Addis Ababa. The source population was all 
healthcare professionals who were working for the public Hospitals in Mekelle city. The study population was randomly selected healthcare professionals who were the employee of public Hospitals in Mekelle city at the time of data collection.

\subsection{Sample Size Determination}

Since there is no study which shows proportion of knowledge sharing practice $\mathrm{p}$ was taken as $=50 \%$ which is prevalence of knowledge sharing practice for the healthcare professionals with 5\% marginal error and 95\% confidence interval. Therefore, the minimum number of sample for the study was calculated, using the formula for single population proportion. A single population proportion formula was used to take the appropriate sample size.

$\mathrm{n}=\mathrm{Z}_{(\alpha / 2)}^{2}$ * $\mathrm{p}(1-\mathrm{p})$ Sample Size determination Equation

Where $\mathrm{n}=$ Minimum sample size required

$\mathrm{z}=$ Standard score corresponding to $95 \%$ confidence interval

$\mathrm{P}=$ Assumed proportion of health care professionals

$\mathrm{D}=$ Margin of error (precision) $5 \%$

$$
\begin{gathered}
0.5(1-0.5) / 0.05^{2} \\
0.5 \times 0.5 / 0.0025 \\
=3.84 \times 0.25 / 0.0025=384
\end{gathered}
$$

Based on this formula with $95 \% \mathrm{CI}, \mathrm{Z} \alpha / 2=1.96, \mathrm{p}=0.5$, $\mathrm{d}=0.05$. Substituting these gives 384 . But the source population was less than 10,000 , i.e., $\mathrm{N}=1000$. So the actual sample size was determined using the following correction formula, which is $\mathrm{nf}=\mathrm{n} /(1+(\mathrm{n} / \mathrm{N}))$

Where $\mathrm{nf}=$ desired sample size

$\mathrm{n}=$ calculated sample size

$\mathrm{N}=$ total population

$\mathrm{nf}=\mathrm{n} /(1+(\mathrm{n} / \mathrm{N}))=384 /(1+(384 / 1000))=277.45 \approx 277$,

Using this adjustment with $10 \%$ non respondent was given 305 respondents. The list of all health care professionals was retrieved from the human resource department of each Hospital and was used as the sampling frame. The total sample size was proportionally distributed to each hospital based on the number of healthcare professionals. Then, the respondents were selected from the Hospitals by using simple random sampling using lottery method.

\section{Results}

\subsection{Socio Demographic Variables of Respondent}

A total of 305 respondents were participated in the study and included in the analysis. Based on the demographics and other personal background information obtained, from the total respondents $160(52.46 \%)$ were females and 145(47.54) males. The highest number of respondents was in the age group of 21-30years 161(52.79\%) and the smallest number of respondents was in the age group less than 20years (1.97\%.).

Regarding to educational level majority of the respondents $153(50.16 \%)$ were first degree holders and most of the respondents $179(58.69 \%$ ) were with working experience of $<=5$ years.

Table 1. Socio Demographic Characteristics of Respondents in Hospitals under Mekelle City $(n=305)$

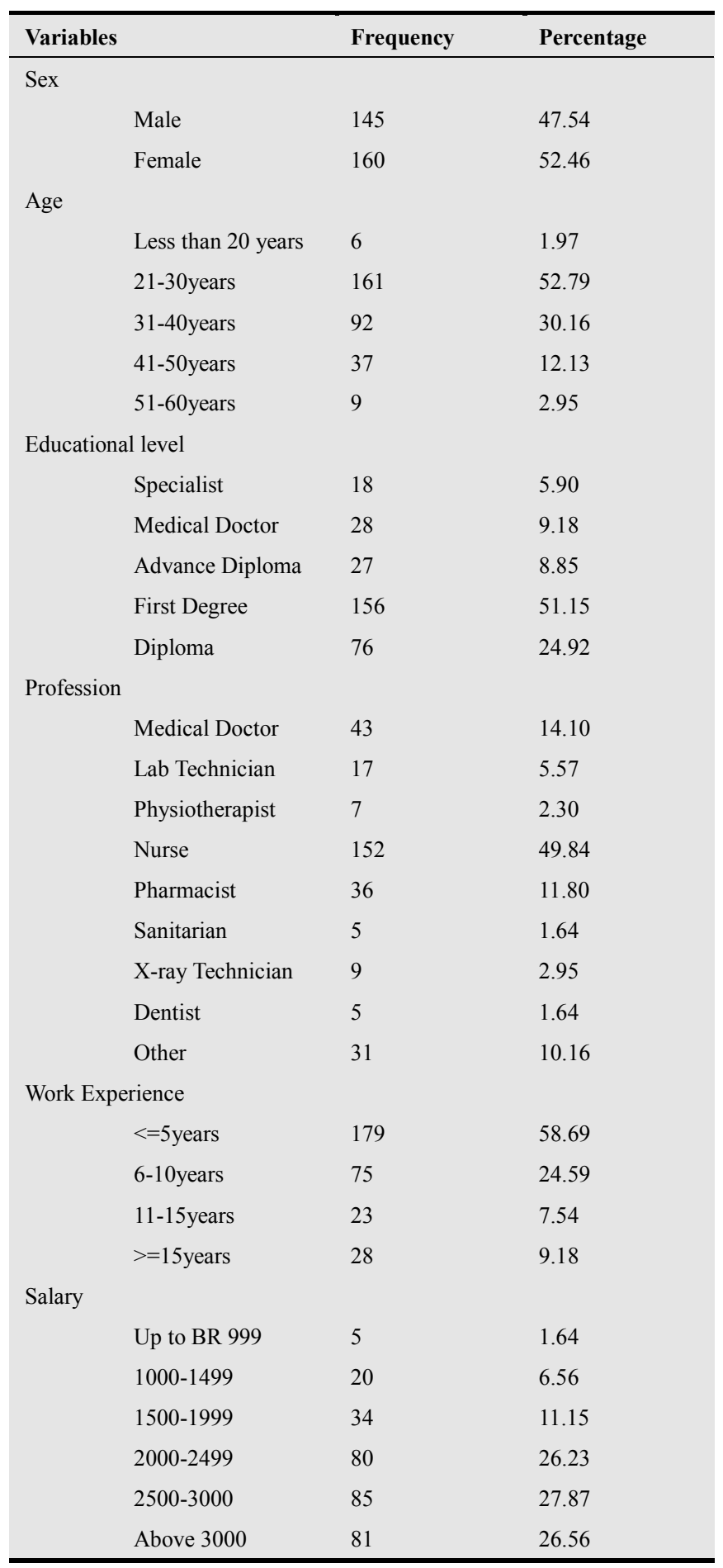




\subsection{Factors Used as Important Incentives to Improve Knowledge Sharing Practice}

Table 2. Factors used as important incentives to improve knowledge sharing practice

\begin{tabular}{cccc}
\hline Variables & Frequency & Percentage \\
\hline Job satisfaction & 194 & 63.61 \\
& Yes & 111 & 36.39 \\
& No & & \\
Motivation & & 15 & 4.92 \\
& Very Low & 39 & 12.79 \\
Low & 102 & 33.44 \\
Medium & 97 & 31.80 \\
High & 52 & 17.05 \\
Very High & 172 & \\
Motivational scheme in the hospital & 56.39 \\
Yes & 133 & 43.61 \\
No & & \\
Documentation & 260 & 85.25 \\
Yes & 45 & 14.75 \\
No & & \\
Salary increment & 43 & 14.10 \\
Very Low & 58 & 19.02 \\
Low & 96 & 31.48 \\
Medium & 50 & 16.39 \\
High & 58 & 19.02 \\
Very High & & \\
\hline & & \\
\hline
\end{tabular}

Table 3. Crude and Adjusted Odds ratio for knowledge sharing practice and selected variables in hospitals under Mekelle city $(n=305)$

\begin{tabular}{|c|c|c|}
\hline Variables & COR $(95 \% \mathrm{CI})$ & $\operatorname{AOR}(95 \% \mathrm{CI})$ \\
\hline \multicolumn{3}{|l|}{ Education level } \\
\hline Diploma & Reference & \\
\hline First Degree & $1.13(0.691,1.873)$ & \\
\hline Medical Doctor & $2.99(1.202,7.455)$ & \\
\hline Specialist & $1.98(0.711,5.514)$ & \\
\hline \multicolumn{3}{|l|}{ Profession } \\
\hline Dentist & 1(Reference) & \\
\hline Lab-Technician & $5.71(0.521,62.658)$ & \\
\hline Medical Doctor & $8.28(0.845,81.189)$ & \\
\hline Nurse & $2.53(0.276,23.258)$ & \\
\hline Pharmacist & $7.07(0.713,70.193)$ & \\
\hline Physiotherapist & $4.66(0.487,44.636)$ & \\
\hline \multicolumn{3}{|l|}{ Salary } \\
\hline $1000-1499$ & Reference & \\
\hline $1500-1999$ & $1.8(0.583,5.554)$ & \\
\hline $2000-2499$ & $1(0.367,2.718)$ & \\
\hline $2500-3000$ & $1.60(0.597,4.334)$ & \\
\hline Above 3000 & $1.84(0.686,4.965)$ & \\
\hline \multicolumn{3}{|c|}{ Respondents Motivation to transfer Knowledge } \\
\hline High & Reference & Reference \\
\hline Low & $0.36(0.166,0.779)$ & $0.54(0.221,1.331)$ \\
\hline Medium & $0.57(0.325,1.005)$ & $0.77(0.402,1.478)$ \\
\hline Very High & $0.75(0.380,1.484)$ & $0.42(0.186,0.981)$ \\
\hline Very Low & $0.04(0.005,0.364)$ & $0.11(0.013,0.988)$ \\
\hline \multicolumn{3}{|c|}{ Motivational Scheme in the Hospital } \\
\hline Yes & $1.95(1.232,3.091)$ & \\
\hline No & Reference & \\
\hline Job Satisfaction & & \\
\hline
\end{tabular}

\begin{tabular}{|c|c|c|}
\hline Variables & COR (95\% CI) & AOR (95\% CI) \\
\hline Yes & $1.83(1.141,2.946)$ & \\
\hline No & Reference & \\
\hline \multicolumn{3}{|l|}{ Salary increment } \\
\hline High & Reference & Reference \\
\hline Low & $0.47(0.214,1.032)$ & $0.41(0.164,1.070)$ \\
\hline Medium & $0.35(0.170,0.719)$ & $0.32(0.140,0.755)$ \\
\hline Very High & $0.54(0.245,1.186)$ & $0.45(0.182,1.137)$ \\
\hline Very Low & $0.25(0.106,0.598)$ & $0.25(0.093,0.696)$ \\
\hline \multicolumn{3}{|c|}{ Technological Dimension } \\
\hline Yes & $1.62(1.026,2.569)$ & \\
\hline No & Reference & \\
\hline \multicolumn{3}{|l|}{ Intrinsic Motivation } \\
\hline Yes & $1.74(1.105,2.755)$ & \\
\hline No & Reference & \\
\hline \multicolumn{3}{|l|}{ Extrinsic Motivation } \\
\hline Yes & $2.30(1.429,3.719)$ & \\
\hline No & Reference & \\
\hline \multicolumn{3}{|c|}{ Supportive Leadership } \\
\hline Yes & $5.75(3.442,9.617)$ & $4.76(2.690,8.435)$ \\
\hline No & 1(Reference) & 1(Reference) \\
\hline \multicolumn{3}{|l|}{ Openness } \\
\hline Yes & $3.31(1.973,5.575)$ & $1.72(0.937,3.159)$ \\
\hline No & Reference & Reference \\
\hline \multicolumn{3}{|l|}{ Willingness } \\
\hline Yes & $3.23(2.022,5.165)$ & \\
\hline No & Reference & \\
\hline \multicolumn{3}{|c|}{ Communication Channel } \\
\hline Yes & $6.77(4.093,11.218)$ & \\
\hline No & Reference & \\
\hline \multicolumn{3}{|c|}{ Knowledge Sharing Opportunity } \\
\hline Yes & $2.82(1.775,4.501)$ & $1.95(1.141,3.342)$ \\
\hline No & Reference & Reference \\
\hline
\end{tabular}

The result showed that most of the respondents 194(63.61\%) reported that they were satisfied with their current job. Almost half 149(48.85\%) of the respondents had high/very high level of motivation knowledge sharing, $172(56.39 \%)$ agree that there is motivational scheme in their hospital for knowledge sharing. The result of the study showed that majority of the respondents $260(85.25 \%)$ were documented their working practices and procedures, whereas, very small number of the respondents 45(14.75) did not document their working practices and procedures on different documenting materials.

\subsection{Determinant Factors Associated with Knowledge Sharing}

Based on the results of Bivariate Regression analysis shown in Table 3, variables which showed significant association with knowledge sharing practice at 5\% significant level were selected for multivariate analysis. In multivariate logistic regression result, odds ratio is the estimated multiplicative change in the odds for a unit change in the predictor variables, controlling for the effects of other predictors.

The significant predictors of knowledge sharing practice at hospitals at 5\% significant level after controlling for the 
effects of others predictors were; respondents motivation to transfer knowledge at low, medium, very high and very low levels, salary increment, supportive leadership, openness, knowledge sharing opportunity in the hospital.

The motivation of respondents to transfer knowledge at low, medium, very high and very low were $46 \%$ $(\mathrm{AOR}=0.54 ; 95 \% \mathrm{CI}=(0.221,1.331)), 33 \% \quad(\mathrm{AOR}=0.77$; $95 \% \mathrm{CI}=(0.402,1.478)), 58 \% \quad(\mathrm{AOR}=0.42 ; 95 \% \mathrm{CI}=$ $(0.186,0.981))$ and $89 \%(\mathrm{AOR}=0.11 ; 95 \% \mathrm{CI}=(0.013$, 0.988)) less likely to practice knowledge sharing respectively compared to those respondents whose motivation to transfer knowledge at high level by holding the effect of variables like salary increment, supportive leadership, openness and knowledge sharing opportunity constant.

Those respondents who believe the importance of salary increment important incentive to share knowledge as low, medium, very high and very low were $59 \%(\mathrm{AOR}=0.41 ; 95 \%$ $\mathrm{CI}=(0.164, \quad 1.070)), \quad 68 \% \quad(\mathrm{AOR}=0.32 ; \quad 95 \% \quad \mathrm{CI}=$ $(0.140,0.755)), 55 \% \quad(\mathrm{AOR}=0.45 ; 95 \% \mathrm{CI}=(0.182,1.137))$ and $75 \%(\mathrm{AOR}=0.25 ;(0.093,0.696))$ less likely to perform knowledge sharing practice respectively compared with those who believe the level of the importance of salary increment as important incentive to share knowledge as high; controlling the effect of other variables (respondents motivation to transfer knowledge, openness, knowledge sharing opportunity and supportive leadership) constant (table 3).

Healthcare professionals who had supportive leadership were $4.76(\mathrm{AOR}=4.76 ; 95 \% \mathrm{CI}=(2.690,8.435))$ times more likely to practice knowledge sharing compared with those who had no supportive leadership by adjusting the other variables as constant.

Those healthcare professionals who were very open and co-operative on job related issues and had a manager who openly explain about policies and rules to team members (Openness) were $72 \%(\mathrm{AOR}=1.72 ; 95 \% \mathrm{CI}=(0.937,3.159))$ more likely to practice knowledge sharing than those professionals who were not very open with their colleagues holding other variables (respondents motivation to transfer knowledge, supportive leadership, salary increment and knowledge sharing opportunity) constant.

Respondents who had knowledge sharing opportunities were $95 \%(\mathrm{AOR}=1.95 ; 95 \% \mathrm{CI}=(1.141,3.342))$ more likely to perform knowledge sharing practice than the respondents who did not have knowledge sharing opportunity by controlling the variables motivation to transfer knowledge, openness, salary increment, and supportive leader ship constant (table 3 ).

\section{Discussion}

The main purpose of this research was to investigate the knowledge sharing practice of healthcare professionals and to identify the main factors that affect knowledge sharing practice among healthcare professionals in the Hospitals under Mekelle city.
The result of the study showed that, out of the 305 study participants $150(49.18 \%)$ of healthcare professionals was participated in the knowledge sharing practice by sharing their knowledge to those healthcare professionals working together, this was almost similar with the result of the study conducted in hospitals under Addis Ababa health bureau which was $(50.3 \%)$ of the health care professionals were frequently participated in knowledge sharing practice (28).

Identifying factors that encourage or discourage knowledge sharing practices in organizations in general and the hospitals under study in particular; is important to investigate ways to increase the use of knowledge that already exists in the hospitals. The factors affecting knowledge sharing could be categorized into three factors: individual, organizational and technological factors (29).

The healthcare professionals' motivation to transfer knowledge was taken as a determinant factor of the knowledge sharing practice in this study. Individuals should be motivated to transfer their knowledge with their colleagues in the hospital (10).

The result of this study confirmed that most $33.44 \%$ of the respondents had medium level of motivation to transfer their experiences and skills to their staffs. This result was smaller than the result of the study conducted in Addis Ababa which was $(41.5 \%)$ of the study participants were motivated to transfer their knowledge to their colleagues. In addition, this variable was found as independent predictor of knowledge sharing practice in multivariate analysis which was consistent with study conducted in Addis Ababa (28).

The organizational factors supportive leadership, openness and knowledge sharing opportunity used in this study were found as independent predictors in the multivariate analysis. Regarding to the supportive leadership the result of the study showed that; majority $61.64 \%$ of the healthcare professionals agreed as there was no supportive leadership from their managers that encourages them to participate in knowledge sharing practice. This result was almost similar with the result of the same study conducted in the hospitals under Addis Ababa health bureau, which was $63.2 \%$ of respondents, disagreed with the presence of supportive leadership in their hospital that encourages them to perform knowledge sharing practice.

Concerning the predictor variable openness, the result of the study revealed that, $210(68.85 \%)$ of the respondent's agreed/strongly agreed on the presence of open communication within their hospital. The result found in this study was greater than the result of the same study conducted in the governmental hospitals of Addis Ababa health bureau, which was $54 \%$ of the respondent's agreed/strongly agreed on the availability of open communication among the healthcare professionals in their organization. Both supportive leadership and openness were not selected as predictor variables in the study conducted in Addis Ababa; this difference might be happened because of the difference in study area and study participants. 
The availability of knowledge sharing opportunity in the hospitals under study was one of the factors that have been used in the study. Accordingly, 52.46\% of the professionals agreed that there were formal knowledge sharing opportunity (trainings, work teams) and informal knowledge sharing opportunities that improve the knowledge sharing practice among them. The result of the study was found to be closely similar with the study conducted in the hospitals under Addis Ababa health bureau which was $56.8 \%$ of the respondents practice knowledge sharing using formal and informal knowledge sharing opportunities. In addition, this variable was found as independent predictor of knowledge sharing practice in multivariate analysis, which was consistent with study conducted in Addis Ababa (28).

Level of salary increment was taken as important incentive for employees to participate in knowledge sharing practice. Based on the result of the study, 35.41\% of respondents greatly agreed that salary increment for healthcare professionals in organizations can improve the need of the employees to practice knowledge sharing. But in the study conducted in Addis Ababa University salary increment was found as a least important incentive of employees to participate in knowledge sharing practice. In addition, it was not independent predictor of healthcare professionals in the multivariate analysis in the study in contrast to this study (28).

\section{Conclusion}

Healthcare professionals are the knowledge creators within the hospital and the produced knowledge should be translated into organizational knowledge; this requires effective knowledge sharing management and knowledge sharing practice. Based on the result of the study and summary, it could be concluded that the almost half of the healthcare professionals in the hospitals were participated in knowledge sharing practice and the supportive leadership of managers in the hospital, the open communication among healthcare professionals related to job issues, the presence of knowledge sharing opportunity in the hospital, salary increment as important incentive to encourage employees, professionals motivation to transfer knowledge were the significant predictors that affect healthcare professionals knowledge sharing practice in the hospitals under study.

\section{Acknowledgment}

We are thankful to the data collectors, health professionals who participated in this study. Hospitals who allow us to conduct this study and Tigray regional health bureau. We are grateful also to Mekelle University for funding the research.

\section{References}

[1] Nakkiran, N. and A. David. (2003) An investigation of knowledge management implementation strategies, Proceedings of SAICSIT; 24-36.

[2] Adhikari, D.R. (2010) Knowledge management in academic institutions, International Journal of Educational Management 24, 2: 94-104

[3] Hooff, B. van den, \& de Leeuw van Weenen, F. (2004) Committed to share: Commitment and $\mathrm{MC}$ use as antecedents of knowledge sharing. Knowledge and Process Management 11, 13-24.

[4] Kogut, B., \& Zander U. (1992) Knowledge of the firm, combinative capabilities, and the replication of technology. Organization Science 3, 383-397.

[5] Kwong, E. and W.B. Lee. (2009) Knowledge elicitation in reliability management in the airline industry, Journal of Knowledge Management; 13, 2: 35-48.

[6] Aulawi, H., Iman, Kadarsah, Rajesri. (2009) Knowledge Sharing Behavior, Antecedent and Their Impact on the Individual Innovation Capability, Journal of Applied Sciences Research 5, 12: 2238-2246.

[7] Abidi S. (2001) Knowledge management in healthcare: towards 'knowledge-driven' decision -support services. International Journal of Medical Informatics 63(1-2): 5-18.

[8] Adem A. (2010) Knowledge sharing among health professionals the case of Felegehiwot referral hospital Bahirdar. Addis Ababa University.

[9] Addis Ababa Health Bureau (2011) Report of Human resource department. Addis Ababa.

[10] Ipe M. (2003) Knowledge Sharing in Organizations: A Conceptual Framework, Human Resource Development Review 2(4): 337-359.

[11] Berends, van der Bij, Debackere and Weggeman.(2006) Knowledge sharing mechanisms in industrial research, R\&D Management 36, 1: 85-95.

[12] Adenfelt, M. and Katarina Lagerstrom. (2006) Enabling knowledge creation and sharing in transnational projects, International Journal of Project Management 24, 3: 191-198.

[13] Liao, S.H., J.C. Chang, S.C. Cheng and C.M. Kuo. (2004) Employee relationship and knowledge sharing: A case study of a Taiwanese finance and securities firm, Knowledge Management Research and Practice 2: 24-34.

[14] Herschel, R.T., H. Nemati and D. Steiger. (2001) Tacit to explicit knowledge conversion: knowledge exchange protocols, Journal of Knowledge Management 5, 1: 107-116.

[15] Kidwell, J.J., K.M.V. Linde and S.L. Johnson. (2000) Applying corporate knowledge management practices in higher education, Educause Quarterly, 4: 28-33.

[16] Al-Hawamdeh, S. (2003) Knowledge Management: Cultivating knowledge professionals. Oxford: Chandos Publishing. 
[17] Allee, V. (1997) Twelve principles of knowledge management, Training and Development 51, 11: 71-74.

[18] Alavi, M. and Dorothy E. Leidner. (1999) Knowledge management systems: Issues, challenges, and benefits. Communications of AIS 1, 7:1-37.

[19] Hogel, M., K.P. Parboteeah and C.L. Munson. (2003) Teamlevel antecedents of individuals' knowledge networks, Decision Sciences 34, 4: 741-770.

[20] Christensen, P.H. (2007) Knowledge sharing: moving away from the obsession with best practices, Journal of Knowledge Management 11, 1: 36-47.

[21] Gurteen, D. (1999) Creating a Knowledge Sharing Culture. Provide sedge [online] Available http://www.kmeljournal.org/ojs/index.php/online publicatio n/article/viewFile/14/21, [accessd on February 2, 2013].

[22] Mitchell, H. (2005) Knowledge sharing the value of Storytelling. International Journal of Organizational Behavior, 9(5), 632-641.

[23] Kim, S. and H. Lee. (2005) Employee knowledge sharing capabilities in public and private organizations: Does organizational context matter? Proceedings of the 38th Hawaii International Conference on System Sciences: 1-10.
[24] Ölçer, F. (2007) Practice of knowledge management in companies: A Turkey survey, Proceedings of IKNOW '07: 254-263.

[25] Hsiu-Fen L. (2007) Knowledge sharing and firm innovation capability: an empirical study. International journal of manpower; 28(3/4): 315-332.

[26] McDermott, R., \& O'Dell, C. (2001) Overcoming cultural barriers to sharing knowledge. Journal of Knowledge Management, 5(1), 76-85.

[27] French, N. (2010) Factors Which Influence Organizational Knowledge Sharing: Available http://upetd.up.ac.za/thesis/available/etd04052011_125919/u nrestricted/dissertation.pdf [accessed on February $\overline{2}$, 2013].

[28] Yalow, T. (2011) Assessment of Knowledge Sharing Practices Among Healthcare Professionals.

[29] Riege A. (2005) Three-Dozen Knowledge-Sharing Barriers Managers must consider. Journal of Knowledge Management 9 (3): 19-33.

[30] Mohd B, Zawiyah M. (2009) Demographic Factors and Knowledge Sharing Quality among Malaysian Government Officers. Communications of the IBIMA; 9: 1943-7765. 